\title{
Research
}

\section{Density dependence, prey accessibility and prey depletion by fisheries drive Peruvian seabird population dynamics}

\author{
Christophe Barbraud, Arnaud Bertrand, Marilú Bouchón, Alexis Chaigneau, Karine Delord, \\ Hervé Demarcq, Olivier Gimenez, Mariano Gutiérrez Torero, Dimitri Gutiérrez, Ricardo Oliveros-Ramos, \\ Giannina Passuni, Yann Tremblay and Sophie Bertrand
}

C. Barbraud (http://orcid.org/0000-0003-0146-212X) (barbraud@cebc.cnrs.fr), K. Delord and G. Passuni, Centre d'Etudes Biologiques de Chizé, UMR 7372, Centre National de la Recherche Scientifique, FR-79360 Villiers en Bois, France. - GP, A. Bertrand, H. Demarcq, Y. Tremblay and S. Bertrand, Inst. de Recherche pour le Développement (IRD), UMR248 MARBEC IRD/CNRS/IFREMER/UM, Sète Cedex, France. - GP, YT, AB, SB, M. Bouchón, A. Chaigneau, D. Gutiérrez and R. Oliveros-Ramos, Inst. del Mar del Perú, Esquina Gamarra y General Valle S/N Chucuito, Callao, Lima, Perú. AC also at: Lab. d'Etudes en Géophysique et Océanographie Spatiale, UMR CNRS, CNES, IRD, Univ. Paul Sabatier, Toulouse, France. - O. Gimenez, Centre d'Ecologie Fonctionnelle et Evolutive, Campus CNRS, UMR 5175, Montpellier Cedex, France. - M. Gutiérrez Torero, Univ. Nacional Federico Villarreal, Lima, Perú.

\section{Ecography}

41: 1092-1102, 2018

doi: $10.1111 /$ ecog.02485

Subject Editor:

Jean-Michel Gaillard Editor-in-Chief: Miguel Araújo

Accepted 4 September 2017

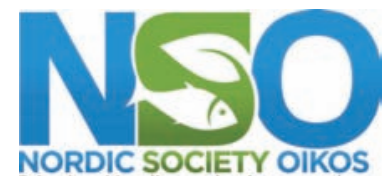

www.ecography.org
In marine ecosystems top predator populations are shaped by environmental factors affecting their prey abundance. Coupling top predators' population studies with independent records of prey abundance suggests that prey fluctuations affect fecundity parameters and abundance of their predators. However, prey may be abundant but inaccessible to their predators and a major challenge is to determine the relative importance of prey accessibility in shaping seabird populations. In addition, disentangling the effects of prey abundance and accessibility from the effects of prey removal by fisheries, while accounting for density dependence, remains challenging for marine top predators. Here, we investigate how climate, population density, and the accessibility and removal of prey (the Peruvian anchovy Engraulis ringens) by fisheries influence the population dynamics of the largest sedentary seabird community ( $\approx 4$ million individuals belonging to guanay cormorant Phalacrocorax bougainvillii, Peruvian booby Sula variegata and Peruvian pelican Pelecanus thagus) of the northern Humboldt Current System over the past half-century. Using Gompertz state-space models we found strong evidence for density dependence in abundance for the three seabird species. After accounting for density dependence, sea surface temperature, prey accessibility (defined by the depth of the upper limit of the subsurface oxygen minimum zone) and prey removal by fisheries were retained as the best predictors of annual population size across species. These factors affected seabird abundance the current year and with year lags, suggesting effects on several demographic parameters including breeding propensity and adult survival. These findings highlight the effects of prey accessibility and fishery removals on seabird populations in marine ecosystems. This will help refine management objectives of marine ecosystems in order to ensure sufficient biomass of forage fish to avoid constraining seabird population dynamics, while taking into account of the effects of environmental variability. 


\section{Introduction}

In marine ecosystems, top predators such as seabirds and marine mammals congregate to feed in areas of high prey availability (Hunt and Schneider 1987, Shealer 2002). There is increasing evidence that physical oceanographic processes concentrate prey for these top predators over a variety of spatial and temporal scales (Shealer 2002, Bertrand et al. 2014). For example, seabirds forage at physical features that enhance prey accessibility in the vertical or horizontal dimension, such as strongly stratified pycnoclines or oxyclines (Hunt et al. 1999, Bertrand et al. 2014) or oceanographic fronts (Bost et al. 2009, Tew Kai et al. 2009). These physical features are affected by global climate change (Diaz and Rosenberg 2008, Stramma et al. 2008), which may affect top predator species and therefore marine ecosystems through cascading effects (Estes et al. 2011). Nonetheless, linking top predator dynamics to variations of environmental factors affecting prey abundance and accessibility has proven difficult as independent information on prey abundance and accessibility is scarce. Some studies have assessed the impact of prey abundance on seabird populations (Frederiksen et al. 2004, Furness 2007, Cury et al. 2011, Bustnes et al. 2013), yet prey may be abundant but inaccessible to their predators and a major challenge is to determine the importance of prey accessibility in shaping seabird populations (Ashmole 1963). In addition to these density-independent factors, the role of density-dependence in the regulation of seabird populations has seldom been investigated and disentangled from the role of density-independent factors, although this is important for conservation (Turchin 1999, Lebreton 2009).

Here, we ask how climate, population density, and the accessibility and removal of prey by fisheries influence the population dynamics across the largest sedentary seabird community of the northern Humboldt Current System (NHCS) over the past half-century. The NHCS off the coast of Peru is a site of year-round wind-driven intense coastal upwelling, which is associated with a high biological activity and a rich ecosystem (Chavez et al. 2008). The NHCS hosts huge, although variable, seabird populations (from $\approx 0.5$ to 16 million individuals), including the guanay cormorant Phalacrocorax bougainvillii, the Peruvian booby Sula variegata and the Peruvian pelican Pelecanus thagus, which are the most abundant seabirds in the Peruvian coastal region (Murphy 1936, Jahncke et al. 2004). These species feed almost exclusively on one to two years old Peruvian anchovy Engraulis ringens (Jahncke et al. 2004). The relative importance of anchovies in the diet of the guanay cormorants, Peruvian boobies and Peruvian pelicans is $81-96 \%, 80-93 \%$ and $>80 \%$ respectively (Jordán 1967, Zavalaga et al. 2011). The NHCS also supports one of the biggest forage fish populations, the Peruvian anchovy, and the world-leading monospecific fishery in terms of landings (over 5 million tonnes annually since the early 1990s and up to 16 million tonnes in the 1970s). The NHCS experiences very high environmental variability at a variety of spatiotemporal scales, from intraseasonal to interdecadal fluctuations (Duffy 1983, Chavez et al. 2008). At interannual scales, during El Niño events was reported nesting failure, mortality of chicks and juveniles, and during extreme El Nińo events (1982-1983) mortality of adults (Tovar et al. 1987, Duffy 1990, Jahncke 1998, Schreiber 2002, Stenseth et al. 2002). However, apart from the impact of these events, much less is known about the impact of interannual variability of the NHCS on seabird populations (Schreiber 2002). In particular, the NHCS is characterized by the presence of one of the world's shallowest and most intense subsurface oxygen minimum zones (Paulmier and Ruiz-Pino 2009). The upper limit of this oxygen minimum zone (ULOMZ), which corresponds to the depth at which dissolved oxygen concentration changes rapidly from its near surface values to anoxic levels, heavily constrains anchovy distribution over a wide variety of spatial scales (Bertrand et al. 2011). Because oxygen is close to zero below the ULOMZ, anchovies remain in the well-oxygenated layer between the surface and the ULOMZ. Therefore, a deep ULOMZ increases the available habitat for anchovies, which can move vertically and escape predation, and decreases their accessibility to foraging seabirds.

The present study aims to relate seabird population abundance to environmental covariates in the NHCS from 1961 to 2008. We considered a limited set of oceanographic and fisheries covariates that are most likely to influence availability of anchovies, the main prey of cormorants, boobies and pelicans in Peruvian waters. These included the sea surface temperature (SST), the depth of the upper limit of the oxygen minimum zone (ULOMZ), and the proportion of the anchovy biomass removed by fisheries. Based on previous knowledge on the ecology of the three seabird species and the NHCS upwelling ecosystem we made three main predictions.

First, meta-analyses showed that positive SST anomalies generally affect negatively seabird demographic parameters (Barbraud et al. 2012, Sydeman et al. 2012). SST at the nearcoastal ocean $(0-100 \mathrm{~km})$ reflects the intensity of the NHCS upwelling. Cool conditions are associated with an active upwelling, increased concentration of nutrients, the development of large phytoplankton and zooplankton communities (Rykaczewski and Checkley 2008) and anchovy abundance (Ayón et al. 2011, Bertrand et al. 2011). Therefore, we predicted a negative effect of SST on seabird abundance.

Second, from comprehensive datasets, it was shown that the depth of the ULOMZ affects the abundance as well as the vertical and horizontal distribution of anchovy at a wide variety of spatial scales (Bertrand et al. 2004, 2008, 2011, Gutierrez et al. 2007, Swartzman et al. 2008, Grados et al. 2012). (At interannual time scales, the depth of the ULOMZ determines the depth of anchovy schools, and thus their accessibility to seabirds (Bertrand et al. 2011, 2014). During the day, when cormorants and boobies are foraging, anchovies can migrate vertically but this behaviour is restricted by the ULOMZ (Bertrand et al. 2008). Thus, available habitat for anchovies increases by deepening of the ULOMZ allowing anchovies to migrate to greater depths, 
which may limit their accessibility to seabirds and increase their foraging costs. Therefore, ULOMZ depth constitutes an informative proxy of anchovy accessibility and we predicted a negative relationship between seabird abundance and the depth of the ULOMZ.

Third, the NHCS anchovy fishery is the world-leading monospecific fishery in terms of landings and it was shown that prey abundance affects seabird populations (Frederiksen et al. 2004, Furness 2007, Cury et al. 2011, Bustnes et al. 2013). Bertrand et al. (2012) showed that foraging efficiency of breeding seabirds in the NHCS was affected by fishery removals, which can reach, on a daily basis, at least 100 times the anchovy requirements of seabird colonies. We thus hypothesized that competition between fishing boats and seabird occurred, and predicted a negative relationship between seabird abundance and the proportion of anchovy biomass removed by fishing.

The effects of SST, depth of the ULOMZ, and the proportion of anchovy biomass removed by fishing were investigated using a Gompertz density dependent model to assess the effects of covariates on the abundance of seabirds, while accounting for observation error and process noise in time series of seabird abundances.

\section{Material and methods}

\section{Species abundance data}

Data on species abundance were collected at 29 islands and headlands of coastal Peru from $6^{\circ} \mathrm{S}$ to $14^{\circ} \mathrm{S}$ (Supplementary material Appendix 1 Table A1) where most ( $>84 \%$ in average) of the populations of cormorant, booby and pelican occur (Guillén 1992). Estimates of abundance were derived from maps showing the areas occupied by breeding and non-breeding birds and estimates of densities of these birds (Tovar et al. 1987). Areas of occupation were drawn on graph paper maps by wardens of islands and headlands, and areas of occupation were estimated using a planimeter (Tovar et al. 1987). Different densities were used for each species and for breeding or non-breeding birds (6, 3 and 3 individuals per $\mathrm{m}^{2}$ for breeding guanay cormorant, Peruvian booby and Peruvian pelican respectively birds; 10,5 and 3 individuals per $\mathrm{m}^{2}$ for non-breeding guanay cormorant, Peruvian booby and Peruvian pelican respectively; Jordán 1963). Although 16\% (in average) of the populations was outside the study area, this represented only eight islands and headlands between $14^{\circ} \mathrm{S}$ and $18^{\circ} \mathrm{S}$, of which five were very irregularly occupied. In addition, there is no strong evidence that birds temporally move to these sites situated further south when local conditions at our study area are bad since no strong increases in numbers were observed at these sites during such years.

Abundance estimates are available for each month for the three species between January 1961 and December 1982 (Tovar et al. 1987), between January 1984 and December 1989 (Guillén 1992), and between January 1997 and December 2008 (Goya 2000, Inst. del Mar del Perú and Ministerio de la Producción, unpubl.). For those time periods the mean abundance of the three species per year was calculated and taken to be an estimate of annual population size. In 1983, estimates of the number of adults of the three species were available only for March, May, June and July (Tovar and Cabrera 1985, Jahncke 1998). In 1983, no census was made during the breeding season due to a strong El Niño event that prevented birds from breeding (Duffy 1983). For the years 1990-1996, estimates were available only for March or April, July and November (Jahncke 1998, Crawford and Jahncke 1999), thus including the breeding season of the three species (Tovar and Cabrera 1985, Passuni et al. 2016). Mean values of those years (1983 and 1990-1996) were also calculated and taken to be estimates of annual population sizes. Because abundance data were not available for all months during the years 1983 and 1990-1996, we also performed the analyses without these specific years to test for the robustness of our results.

Abundance data from all islands and headlands were pooled together for the analysis. Indeed, all islands and headlands are situated within the same marine ecosystem (the NHCS) and therefore seabird populations face similar oceanographic conditions. In addition, all islands and headlands have similar landscape and climate (arid and without vegetation), and are all uninhabited.

To investigate correlations between abundance time series data we corrected correlation coefficients between time series for attenuation (Spearman 1904), since our time series of abundances potentially included substantial measurement errors. The disattenuated estimate of the correlation coefficient $r_{p q c}$ between two time series of abundance $p$ and $q$ was calculated as

$r_{p q c}=\frac{r_{p q}}{\sqrt{R_{p} R_{q}}}$

where $r_{p q}$ is the observed correlation coefficient, $R_{p}=\frac{\operatorname{var}(p)}{\operatorname{var}(p)+\sigma_{p}^{2}}$ and $R_{q}=\frac{\operatorname{var}(q)}{\operatorname{var}(q)+\sigma_{q}^{2}}$, with $\operatorname{var}(p)$ and $\operatorname{var}(q)$ the variances of $p$ and $q$, and $\sigma_{p}^{2}$ and $\sigma_{q}^{2}$ the variances of the observation errors for time series $p$ and $q$. Estimates of $\sigma_{p}^{2}$ and $\sigma_{q}^{2}$ were obtained from our state space model (see section Population model) where Eq. 1 was modified as $x_{t+1}=x_{t}+\varepsilon_{t}$. Lower and upper bounds of $95 \%$ confidence sets for corrected correlation coefficients were calculated using Eq. 17 and 18 established by Charles (2005).

\section{Covariates}

Average annual values of SST (in ${ }^{\circ} \mathrm{C}$ ) and ULOMZ (in m) were obtained from in situ vertical profiles acquired by Instituto del Mar del Perú and the World Ocean Database (Garcia et al. 2010) between $7^{\circ} \mathrm{S}$ to $18^{\circ} \mathrm{S}$ and from the coast to $100 \mathrm{~km}$ offshore between 1961 and 2008 (Bertrand et al. 2011). 
The depth of the ULOMZ was defined as the depth where the dissolved oxygen concentration equals $2 \mathrm{ml} \mathrm{l}^{-1}$ $\left(\mathrm{Z}_{2 \mathrm{~m} / / \mathrm{l}}\right)$. At decadal time scales (periods of 10 or more years) the average depth of the ULOMZ is related to the abundance of anchovy as shown in Bertrand et al. (2011).

To estimate the proportion of anchovy biomass removed by fishing we used two variables. First, we used annual time series of landings of anchovies (Land, tonnes landed per year over all harbours from Peru, Ministerio de la Producción, $<$ www.produce.gob.pe $>$ ) provided by IMARPE (<www. imarpe.pe/imarpe $>$ ) for the period 1961-2008. Some under-reporting occurs (Castillo and Mendo 1987, Mendo and Wosnitza-Mendo 2014), so this is a minimum estimate, but we are confident that our catch index reflected the global interannual patterns. Second, we used anchovy secondary production (Prod) estimated by an integrated assessment model using acoustic estimates of biomass and length structure from scientific surveys and fishery landings between $7^{\circ} \mathrm{S}$ and $18^{\circ} \mathrm{S}$ and from the coast to $100 \mathrm{~km}$ offshore (Oliveros-Ramos and Peña 2011). For the estimation of secondary production, for every monthly time step the increase of population biomass due to somatic growth and natality was estimated without considering natural and fishing mortality. From these two variables we calculated the proportion of anchovy biomass removed $(\mathrm{PROP})$ as: $\mathrm{PROP}=1-(\operatorname{Prod}-\mathrm{Land}) /$ Prod.

Our choice for using annual values was motivated by several reasons. First, breeding is not strictly seasonal for the three seabird species as commonly observed for temperate of polar seabird species (Passuni et al. 2016). Although Peruvian boobies and Peruvian pelican mainly breed during a given period of the year (from July to November), breeding may occur during the other months of the year. The Guanay cormorant breeds during an extensive period over a year, mainly from April to December, and can also breed during the other months of the year. Also, there is evidence that changes in breeding seasonality occurred at some sites for the three species during the study period (1961-2008) and that these changes differed between species (Passuni et al. unpubl.). Consequently, using abundance estimated each year at the same period of the year would introduce bias due to differences in breeding seasonality between species and due to changes in breeding seasonality during the study period. Second, our main interest was to investigate interannual patterns in seabird abundance in relation to interannual patterns in environmental parameters. The depth of the ULOMZ varies at a continuum of spatiotemporal scales. High frequency and fine scale variability corresponds to downward deformations of the ULOMZ deepening locally and temporally (Bertrand et al. 2010, 2014). These fine scale processes act at small spatial (a few $\mathrm{km}$ ) and temporal (from hours to a few days) scales and are not expected to affect seabird populations determined by demographic processes operating at larger temporal scales. By contrast, the mean depth of the ULOMZ varies at larger spatiotemporal scales. Spatially there is a deepening of the mean depth of the ULOMZ from the coast to the offshore domain and a sharp deepening north of $\sim 70 \mathrm{~S}$ (Fuenzalida et al. 2009, Bertrand et al. 2010). To account for this pattern we used oxygen data collected south of $7^{\circ} S$ and within the first $100 \mathrm{~km}$ from the coast. Temporally, the mean depth of the ULOMZ varies at interannual and decadal scales (Bertrand et al. 2011) and we used mean annual values. To summarize, seabird populations are unlikely to be affected in their demography by local and ephemeral structures deepening the ULOMZ but more likely by interannual changes in the mean depth of the ULOMZ affecting forage fish accessibility. Third, we were also constrained by the temporal resolution of the data. The major constraint was for ULOMZ data based on 1 or 2 acoustic surveys per year and limited data from the World Ocean Atlas. Note that earlier studies suggested that a monthly estimate of the ULOMZ for a given year reflects well the annual pattern for this parameter (Bertrand et al. 2011). Finally, although part of the seabird data had a monthly resolution, this was not the case for all years, and we had only 3-4 counts per year for some years.

To describe temporal trends of covariates we made no a priori assumptions about the form of any relationships between covariate values and year. We thus used generalized additive models (GAM) specified with a Gaussian family, a penalized thin plate regression spline, and the optimal span for smoothing was determined by AIC (Zuur et al. 2009).

Although it is known that the three species mainly forage on the same prey (anchovy), several studies showed that the foraging strategy or the foraging habitat of the three species strongly differ (Zavalaga and Paredes 1999, Zavalaga et al. 2010, 2011, Weimerskirch et al. 2012). Cormorants are pelagic surface divers exploiting all depths at which anchovy occur, reaching up to $74 \mathrm{~m}$ depth (mean maximum diving depth of $6.3 \mathrm{~m}$ ). Peruvian boobies are plunge divers and only reach shallow anchovy schools (mean maximum diving depth of $1.8 \mathrm{~m}$ ). Both species forage during the day but Peruvian boobies leave the colonies earlier in the morning and return later in the evening than cormorants. Peruvian pelicans forage almost exclusively at night and are surface feeders only using the first 1 or $2 \mathrm{~m}$ of the water column. Together, these studies suggest that this diversity of foraging strategies or foraging habitats reduces inter-specific food competition. Finally, inter-specific competition for nesting space between the three species has not been documented and species have habitat preferences for nesting (Duffy 1983). Therefore, we did not test for inter-specific competition.

\section{Population model}

\section{Process model}

We used the discrete time stochastic Gompertz population model to analyse the strength of density dependence in the data (Dennis and Taper 1994, Lebreton 2009). Writing $N_{\mathrm{t}}$ for the abundance for a given species in year $t$ and $x_{\mathrm{t}}=\ln \left(N_{\mathrm{t}}\right)$ the model is defined through

$x_{t}=r+(1-b) x_{t-1}+\varepsilon_{t}$

where $r=\ln (\lambda)$ is the intrinsic growth rate for $N=1, \lambda$ is the population growth rate defined as $N_{\mathrm{t}} / N_{\mathrm{t}-1}, b$ is a measure of 
the strength of density regulation and $\varepsilon_{\mathrm{t}}$ is a normally distributed process error with mean zero and process variance $\sigma_{\text {proc }}^{2}$. When $b=0$ the process is density independent, and on the log scale is a Gaussian random walk with drift given by $r$, and when $b>0$ the process is density dependent giving a log normal stationary distribution for the population size with mean $r / b$ and variance $\sigma_{\text {proc }}^{2} /(b(2-b))$.

One main goal here is to examine the effect of several environmental covariates on species abundance. To do this we rewrite Eq. 1 as

$x_{t}=r+(1-b) x_{t-1}+\sum_{j=1}^{p} a_{j} z_{t j}+\varepsilon_{t}$

where $z_{t j}$ is covariate $j(j=1, \ldots, p)$ at time $t$ and $a_{\mathrm{j}}$ is the effect of the covariate (Dennis and Otten 2000, Lebreton 2009). Equation 2 models the additive effects of density dependence and of an environmental covariate on abundance. Since environmental covariates were correlated to each other (Supplementary material Appendix 2 Table A2) we used variance inflation factors to assess which explanatory variables were collinear and should be dropped before starting the analyses (Zuur et al. 2009). A cut-off value of 3 was used to remove collinear variables (Supplementary material Appendix 2 Table A3). Because the changes in abundance of seabirds reflect the integration of processes that occur at different temporal scales (Thompson and Ollason 2001), we considered delayed effects of the covariates. Values of one to five years were used for the time lag in the effects of environmental covariates on abundance on the basis of reasonable estimates of the delay between fledging and first reproduction for the three species studied (Nelson 2005).

To test for trends in abundance time series of the three species we used the following model:

$x_{t}=\kappa+\beta \times$ year $r_{t}+\varepsilon_{t}$

where $\kappa$ is an intercept parameter and $\beta$ is a slope parameter.

\section{Observation model}

It is known that regression methods for detecting density dependence neglecting uncertainty in population size cause strong bias in both tests and estimates of strength (Slade 1977, Dennis and Taper 1994, Lebreton 2009). We thus used a state space formulation for our density dependent model to explicitly take into account uncertainty in population abundance estimates following (Bulmer 1975, Dennis et al. 2006, Knape and de Valpine 2012, Lebreton and Gimenez 2013). Given the way abundance data of cormorants, boobies and pelicans were collected we highly suspected that our time series on population abundances had a relatively high level of uncertainty. Observation errors came from a number of sources such as warden experience to report groups of breeding and non-breeding birds on graph paper maps, or variability in density of groups of birds on islands and headlands (density was assumed fixed across years when multiplied to the areas occupied by birds). We modelled uncertainty in population abundance estimates with a log normal distribution in such a way that the log transformed population abundance estimates $y_{1}, \ldots, y_{\mathrm{T}}$ are given by

$$
y_{t}=x_{t}+\eta_{t}
$$

where $\eta_{t+1}$ is normally distributed observation error with mean zero and observation variance $\sigma_{o b s}^{2}$. Thus, the state of the population is described by model 1 or 2 and the observation model 3 .

\section{Priors}

To perform the Bayesian analyses and fit our models, we need to specify a prior for each parameter. Several studies (Lawrence et al. 2013, Lebreton and Gimenez 2013) recently raised caution in choosing parameter priors in model selection in regressive density dependence models. These authors recommended excluding non-meaningful possibilities from the prior, that is, not allowing parameters to take values that would produce behaviour we know does not happen. Therefore, we used uninformative uniform priors for $\sigma_{\text {proc }}$ and $\sigma_{o b s}(\sigma \sim$ unif( $(0,3))$ and $\varepsilon(\varepsilon \sim$ unif $(0,3))$, and for parameters $a_{\mathrm{i}}$ we used Gaussian prior distributions $\left(a_{\mathrm{j}} \sim N(0,3)\right)$. Each chain was initiated by assuming a prior distribution on the initial state centred around the first observation of abundance with standard deviation 0.4, $x_{1} \sim N\left(y_{1}, 0.4\right)$. Several authors (Delean et al. 2013, Lebreton and Gimenez 2013) recommended the choice of a reasonable prior for $r$ based on external comparative information. We used the comparative demographic approach (Niel and Lebreton 2005) to estimate priors for $r$ for cormorants, boobies and pelicans. For each species we used the following formula (Niel and Lebreton 2005) to calculate $r$

$$
r \approx \ln \left(\frac{(s \alpha-s+\alpha+1)+\sqrt{(s-s \alpha-\alpha-1)^{2}-4 s \alpha^{2}}}{2 \alpha}\right)
$$

where $s$ is the adult survival probability and $\alpha$ the mean age at first reproduction. Adult survival probabilities and age at first reproduction were taken from (Nelson 2005), and were respectively for guanay cormorant, Peruvian booby and Peruvian pelican of $0.85,0.90$ and 0.82 and 2.5 years, 2.5 years and 3 years. To generate a prior distribution for $r$, we estimated a mean value for $r$ from Eq. 4 using the above values of age at first breeding and adult survival and choose a standard deviation of 0.02 for $r$. Using larger values for the standard deviation would result in unrealistic values for $r$. Prior distribution for $r$ for guanay cormorant, Peruvian booby and Peruvian pelican were thus $N(0.18,0.02), N(0.16,0.02)$, and $N(0.17,0.02)$. For the trend analyses we used $N(0,100)$ as priors for parameters $\kappa$ and $\beta$.

\section{Model fitting and selection}

Following (Lebreton and Gimenez 2013), models were fit with using a Bayesian approach using Markov chain Monte Carlo (MCMC) simulation implemented in JAGS 
(Plummer 2003, see Supplementary material Appendix 3) via $\mathrm{R}$ (<www.r.project.org $>$ ). For model fitting, we ran each MCMC chain for 200000 iterations with an initial burn-in of 20000 iterations and thinned chains by retaining parameter values from every 10th iteration to reduce the influence of autocorrelation. We used the resulting 9800 values to generate posterior distributions. We ran two chains with different initial values to ensure adequate mixing. All covariates were standardised to facilitate convergence and to allow comparison of effect sizes. We assessed convergence to a stationary distribution by visual inspection of density and trace plots for each model parameter to ensure adequate mixing and by using the Gelman and Rubin diagnostic (R-hat) (Gelman and Rubin 1992). In all cases the estimates for the parameters of interest were highly consistent between chains and R-hat values were under the commonly accepted threshold of 1.1. We summarised posterior distributions of the unknown parameters by their means and $95 \%$ highest posterior density (HPD) intervals. We used the deviance information criterion (DIC) (Spiegelhalter et al. 2002) to compare models and to assess whether the inclusion of covariates improved model fit. A forward selection procedure was performed based on the DIC, selecting the model with the lowest DIC value. Practically, in the first step each covariate and its time lags was considered one by one and the selected covariate was retained in the model. In the following steps, all the remaining covariates and their time lags were iteratively considered for addition. This procedure continued until the model with the lowest DIC was found. GAMs were fitted using the 'mgcv' library and the R package 'gam' (Hastie 2011).

\section{Field estimates of observation error}

To assess the reliability of model-based estimates of observation error and the robustness of our inferences based on state-space models, we performed specific aerial surveys to obtain field estimates of observation error for the three species (Supplementary material Appendix 4).

\section{Results}

We found correlated population fluctuations across all three seabird species (Supplementary material Appendix 5 Table A5). There was evidence for a decrease in abundance of the three species from 1961 to 2008, with a more marked decrease in cormorants and pelicans (Fig. 1, Supplementary material Appendix 6 Table A6). Our time series began after the first developments of the industrial fishery in the late 1950s, with annual catches already above $4 \times 10^{6}$ tonnes in 1961 . As such it allows analysing the effects of variation in the fishing activity, but not its global effect on seabird populations. The
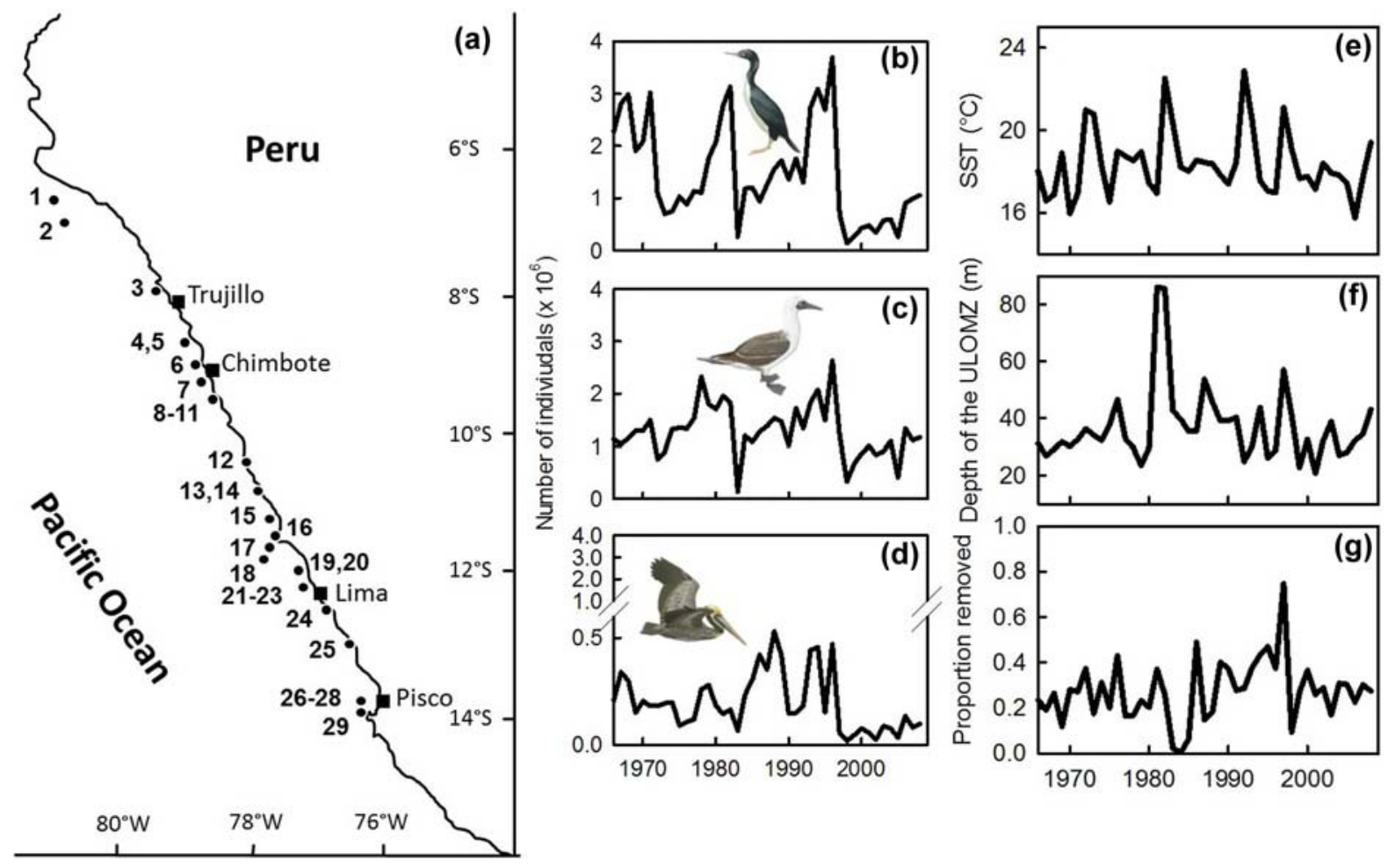

Figure 1. The study system off the coast of Peru and annual fluctuations in abundances of guano-producing seabirds, and of physical and fisheries variables for the period 1966-2008. (a) map of the distribution of islands and headlands monitored annually for the abundance of seabirds (Supplementary material Appendix 1 Table A1), (b) guanay cormorant, (c) Peruvian booby, (d) Peruvian pelican, (e) sea surface temperature, (f) depth of the ULOMZ, (g) proportion of anchovy biomass removed by fishing. 
mean depth of the ULOMZ averaged over the first $100 \mathrm{~km}$ from the coast deepened from $\approx 35 \mathrm{~m}$ at the beginning of the 1960s to more than $50 \mathrm{~m}$ at the mid-1980s and then slightly shoaled again to reach $45 \mathrm{~m}$ at the end of the 2000s $(p=0.017$, Supplementary material Appendix 7 Fig. A7, Table A7). Mean SST did not show statistically significant trends during the study period $(p=0.165)$. Catches of anchovy decreased from $\approx 7.2$ million tonnes annually in the early 1960 s down to $\approx 0.8$ million tonnes annually in the early 1980 s, increased up to $\approx 9$ million tonnes at the beginning of the 2000s and stabilized at $\approx 6.5$ million tonnes annually by the end of the 2000s. Anchovy biomass increased up to $\approx 16$ million tonnes in the early 1970 s, then decreased down to $\approx 2$ million tonnes in the early 1980 s and increased up to $\approx 10$ million tonnes by the end of the 2000s. The proportion of anchovy biomass removed by fishing tended to increase from $20 \%$ in the early 1960 s up to a maximum of $74.8 \%$ in 1997 $(p=0.068)$ and was in average $26 \%$ since 1998 .

The selected state-space models estimated population sizes that were close to the observed population counts (Fig. 2). Model fit was high for guanay cormorants and Peruvian pelicans $\left(R^{2}>0.92\right)$, and slightly lower for Peruvian boobies $\left(R^{2}=0.706\right)$. Estimated observation error obtained by state-space models was similar to observation error estimated by aerial surveys (Supplementary material Appendix 4 Table A4). Model selection suggested strong evidence for density dependence in abundance of the three seabird species (Table 1, Supplementary material Appendix 8 Table A8). The strength of density dependence was similar for all seabird species (Table 2). After accounting for density dependence and for the study period that falls entirely within the industrial fishing era, there was evidence for an effect of the depth of the ULOMZ with a one year lag on annual population sizes of cormorants and boobies, and of a moderate unlagged effect of the ULOMZ on the annual population size of pelicans. The depth of the ULOMZ had a negative effect on all species' populations, with higher populations when ULOMZ had been shallow the previous year (cormorants, boobies) or the current year (pelicans) (Table 2). SST without lag had a negative effect on the population size of cormorants, but the effect was moderate for boobies, and was not detected for pelicans. Prey removal with a one year lag (i.e. the proportion of anchovy biomass removed by fishing) negatively affected the population sizes of guanay cormorants and Peruvian boobies (Table 1). Model selection was not affected when removing the years 1983 and 1990-1996 from the data (Supplementary material Appendix 9 Table A9).

\section{Discussion}

The state-space models allowed using the seabird counts collected over nearly 50 years while accounting for their high uncertainty when testing for the ecological processes at work. Because the estimated observation error was very similar to the one estimated in the field, and since the models fitted reasonably well the data, we are confident that it was correctly
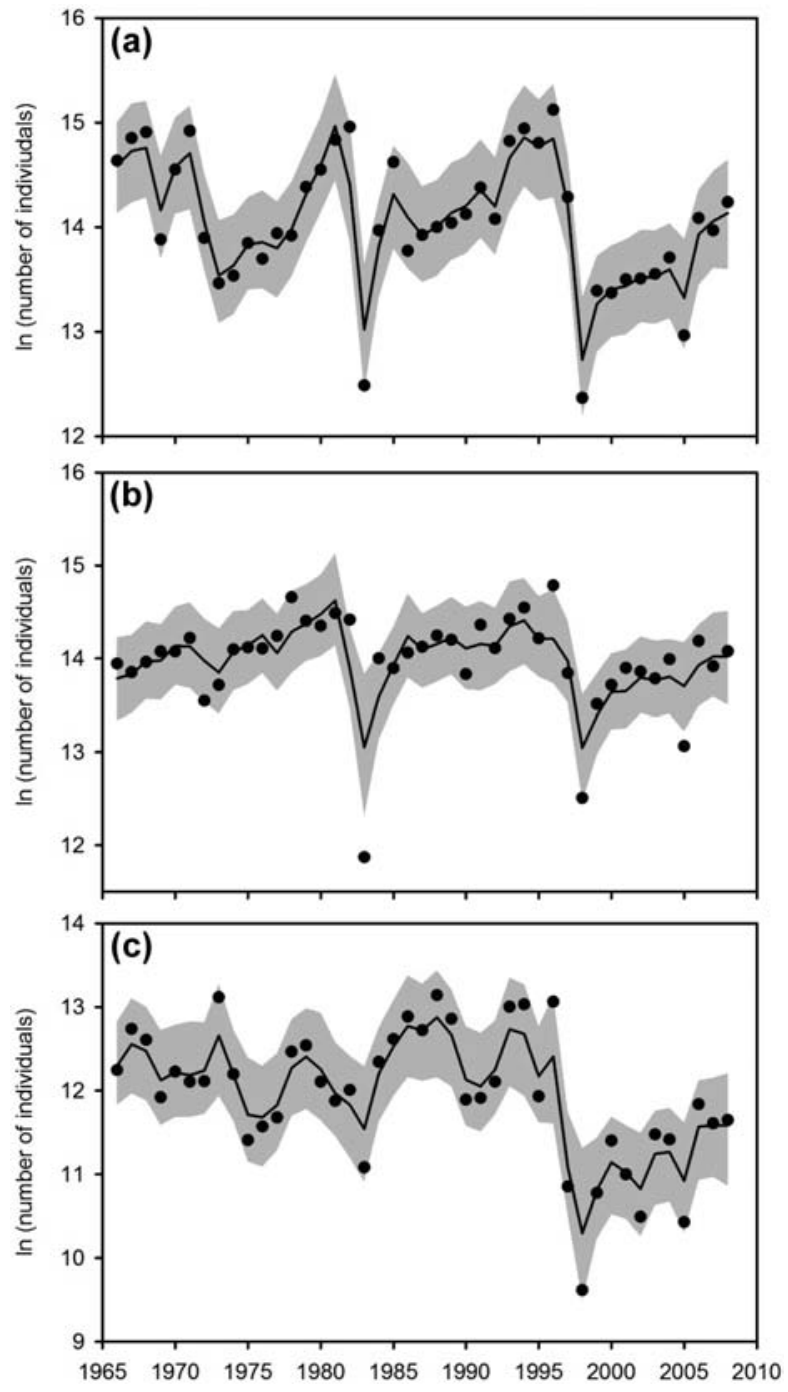

Figure 2. The observed counts of guanay cormorants (a), Peruvian boobies (b) and Peruvian pelicans (c) from 1966 to 2008 (filled circles), the estimated abundance based on the best model selected for each species (Table 1) including an effect of density dependence and covariates (solid line). The grey shaded area represent the $95 \%$ highest probability density (HPD) intervals.

taken into account in our models and that our results are robust.

One covariate was negatively linked to the abundance of each seabird species: the depth of the ULOMZ, although the evidence was less strong for pelicans. This suggests that the underlying ecological mechanism through which the depth of the ULOMZ affected seabird abundance was linked to prey accessibility. First, although anchovy biomass increased tremendously since the early 1980s there was no increase in seabird populations (Fig. 1), suggesting the existence of other limiting factors such as food limitation due to fisheries catches, limited nesting areas or disturbance by guano-collecting. However, the two latter causes are unlikely since nesting areas remained unchanged since the early 1980s and guano-collecting is mainly done outside the 
Table 1. Final models selected for explaining variation in abundance of guanay cormorants, Peruvian boobies and Peruvian pelicans.

\begin{tabular}{ll}
\hline Model & DIC \\
\hline Cormorant & \\
$\quad$ Selected model: DD $+\mathrm{SST}_{0}+\mathrm{ULOMZ}_{1}+\mathrm{PROP}_{1}$ & 44.6 \\
$\quad$ Model without covariate: DD & 69.9 \\
Booby & \\
$\quad$ Selected model: DD $+\mathrm{SST}_{0}+\mathrm{ULOMZ}_{1}+\mathrm{PROP}_{1}$ & 54.2 \\
$\quad$ Model without covariate: DD & 67.9 \\
Pelican & \\
$\quad$ Selected model: DD + ULOMZ & 61.9 \\
$\quad$ Model without covariate: DD & 69.2 \\
\hline
\end{tabular}

$\mathrm{DIC}=$ deviance information criterion; $\mathrm{DD}=$ density dependence; SST = sea surface temperature; $U L O M Z=$ depth of the upper limit of the oxygen minimum zone; $\mathrm{PROP}=$ proportion of anchovies removed by fishing. Subscript indicates time lag in number of years.

main breeding season (Duffy 1994). Second, primary production and anchovy abundance flourish when ULOMZ is shallow, which also corresponds to poor visibility for seabirds (the high primary production in the water column increases the number of phytoplankton organisms in suspension). Also, the studied seabird species mainly forage on the coastal areas (Zavalaga et al. 2011, Bertrand et al. 2012, Weimerskirch et al. 2012) where the upwelling is strong and water is turbid, and not in the less productive and clearer oceanic waters (Swartzman et al. 2008). We can then discard the hypothesis that shallow ULOMZ is beneficial

Table 2. Estimates and 95\% highest posterior density (HPD) of the parameters for the selected model for each species. $b=$ strength of density regulation, $a_{1}=$ effect of $\mathrm{SST}_{0}, a_{2}=$ effect of $U L O M Z_{1}$, $a_{3}=$ effect of PROP $1, a_{4}=$ effect of $\mathrm{ULOMZ}_{0}, \sigma_{o b s}^{2}=$ the observation variance, $\sigma_{\text {proc }}^{2}=$ the process variance, $\operatorname{Pr}(\theta>0)=$ the probability that the parameter $\theta$ is positive, $\operatorname{Pr}(\theta<0)=$ the probability that the parameter $\theta$ is negative.

\begin{tabular}{|c|c|c|c|c|c|}
\hline Parameter & Estimate & $\begin{array}{l}2.5 \% \\
\text { HPD }\end{array}$ & $\begin{array}{c}97.5 \% \\
\text { HPD }\end{array}$ & $\operatorname{Pr}(\theta<0)$ & $\operatorname{Pr}(\theta>0)$ \\
\hline \multicolumn{6}{|l|}{ Guanay cormorant } \\
\hline$b$ & 0.013 & 0.004 & 0.024 & & 0.993 \\
\hline$a_{1}\left(S_{S T}\right)$ & -0.144 & -0.348 & 0.067 & 0.918 & \\
\hline$a_{2}\left(U_{L O M Z}\right)$ & -0.142 & -0.321 & 0.041 & 0.940 & \\
\hline$a_{3}\left(\mathrm{PROP}_{1}\right)$ & -0.207 & -0.392 & -0.043 & 0.991 & \\
\hline$\sigma_{o b s}^{2}$ & 0.308 & 0.091 & 0.505 & & \\
\hline$\sigma_{\text {proc }}^{2}$ & 0.427 & 0.220 & 0.654 & & \\
\hline \multicolumn{6}{|l|}{ Peruvian booby } \\
\hline$b$ & 0.011 & 0.005 & 0.017 & & 0.998 \\
\hline$a_{1}\left(\mathrm{SST}_{0}\right)$ & -0.030 & -0.199 & 0.146 & 0.634 & \\
\hline$a_{2}\left(U L O M Z_{1}\right)$ & -0.154 & -0.295 & -0.007 & 0.984 & \\
\hline$a_{3}\left(\mathrm{PROP}_{1}\right)$ & -0.171 & -0.309 & -0.039 & 0.996 & \\
\hline$\sigma_{o b s}^{2}$ & 0.382 & 0.253 & 0.525 & & \\
\hline$\sigma_{\text {proc }}^{2}$ & 0.236 & 0.036 & 0.444 & & \\
\hline \multicolumn{6}{|l|}{ Peruvian pelican } \\
\hline$b$ & 0.016 & 0.002 & 0.032 & & 0.9843 \\
\hline$a_{4}\left(\mathrm{ULOMZ}_{0}\right)$ & -0.115 & -0.321 & 0.085 & 0.872 & \\
\hline$\sigma_{o b s}^{2}$ & 0.389 & 0.050 & 0.661 & & \\
\hline$\sigma_{p r o c}^{2}$ & 0.522 & 0.214 & 0.845 & & \\
\hline
\end{tabular}

to seabird by making anchovy more easily detectable, and exclude visibility as a confounding factor. In the NHCS, deeper ULOMZ offers greater vertical habitat for anchovies that can more easily avoid predation by diving seabirds. Most seabirds forage (at least during breeding) in a narrow band from the coast $(0-25 \mathrm{~km})$ where ULOMZ depth is classically shallow (10-30 m; Bertrand et al. 2011) and that corresponds to the favored habitat of anchovy (Swartzman et al. 2008), thus well within the diving capacity of cormorants and boobies (Zavalaga et al. 2010, 2011, Bertrand et al. 2012, Weimerskirch et al. 2012). Peruvian boobies can reach a maximum depth of $\approx 10 \mathrm{~m}$ (Weimerskirch et al. 2012), and although guanay cormorants can dive down to $\approx 35 \mathrm{~m}$ (Weimerskirch et al. 2012), a deeper ULOMZ may force seabirds to dive deeper to access prey and increase the associated energetic costs (Enstipp et al. 2006). Increased foraging effort may negatively impact feeding frequencies of chicks and breeding success as shown in the Adélie penguin Pygoscelis adeliae in Antarctica (Balance et al. 2009), as well as survival of juvenile individuals that are less proficient foragers than adults as shown for the European shag Phalacrocorax artistotelis in the North Sea (Daunt et al. 2007), among others (Wunderle 1991), and ultimately population size. In addition, in the NHCS extremely deep ULOMZ occurs during strong El Nińo events (e.g. 1982-1983 and 1997-1998 on Fig. 1), during which anchovy is scarce and poorly accessible, resulting in seabird population crashes (Schreiber and Schreiber 1984).

The different time lags between the depth of the ULOMZ and the abundance of seabirds suggest that different underlying demographic processes were involved. For pelicans, the absence of a lag effect suggests that a deeper ULOMZ may directly affect breeding propensity and thus the number of breeders counted on islands and headlands. The one year lag effect for the two other species rather suggest that a deeper ULOMZ may increase adult mortality after breeding and/or may induce carryover effects on adult condition the following breeding season, leading to a decreased breeding propensity.

The proportion of anchovy biomass removed by fishing was also negatively related to the abundance of guanay cormorants and Peruvian boobies. This strongly suggests that fisheries catches of anchovy limited the amount of resources available for seabirds with significant demographic impacts. The one year lag effect of this covariate on the abundance of cormorants and boobies may also corresponds to an increased adult mortality after breeding (due to the high energetic costs of breeding induced by the removal of anchovies by the fishery) and/or to carryover effects on adult condition the following breeding season, leading to a decreased breeding propensity. The average proportion of anchovy biomass in the ecosystem removed by fisheries during the study period represented $\approx 26 \%$ (minimum $0.3 \%$, maximum $74.8 \%$ ). Although this was slightly lower, in average, than the identified threshold $(\approx 35 \%$, 95\% confidence interval 31 to $39 \%$ ) in prey abundance below which seabirds experience reduced productivity (Cury et al. 2011), 
this threshold did not integrate the effect of prey removal on other demographic parameters and population growth rate, and the threshold was exceeded during 14 years $(29 \%)$ of the study period. In addition, from a behavioural perspective, it has been shown that breeding seabirds in the NCHS need to forage farther from their nest to cope with the regional prey depletion created by the important anchovy removals by the fishery (Bertrand et al. 2012), which may negatively impact chick provisioning, growth rates and ultimately breeding success.

The other oceanographic factor that impacted the abundance of seabirds was SST, but this only concerned cormorants and the evidence was not strong. SST is closely related to the strength of the upwelling intensity and biological productivity in the NHCS and Passuni et al. (2016) showed that breeding of cormorants mainly stopped when SST are warm. Passuni et al. (2016) also suggested that seabirds in the NHCS possibly used SST as an environmental cue to initiate breeding. Therefore, we can hypothesize that warm SST negatively impact the breeding propensity of cormorants.

In addition to oceanographic factors and fisheries activities, our study showed that negative direct density dependence was present in the dynamics of the three seabird species. The detection of density dependence in seabirds has seldom been demonstrated using robust methods. Although further research is needed to understand the underlying mechanisms leading to the density-dependent responses detected here, regional prey depletion created by the fishery may also enhance intra-specific competition by forcing seabirds to forage further from the colonies as shown for the Peruvian booby (Bertrand et al. 2012). Limitation of suitable breeding sites is an unlikely density-dependent factor influencing cormorant, booby and pelican dynamics given the large number of available islands, some of them only episodically occupied by breeders (Passuni et al. 2016).

Our selected models predicted relatively well the dynamics of guanay cormorant and Peruvian pelicans, but the predicted power was less good for Peruvian boobies, mainly because the model had difficulties predicting major population crashes such as in 1983 and 1998. These years corresponded to the two most important El Niño events ever recorded. These population crashes may reflect massive migration outside the study area during these years, particularly for Peruvian boobies for which large numbers were observed in waters outside their normal range during the 1982-1983 El Niño event (Herdson 1984, Aid et al. 1985, Hughes 1985, Ainley et al. 1988). Since the processes of emigration and immigration were not explicitly taken into account in our Gompertz models, this may explain its poorer performance to predict these population crashes.

So far, climate changes have been shown to affect marine top predator dynamics and a handful of studies have identified an impact of prey abundance on seabird populations (Frederiksen et al. 2004, Furness 2007, Cury et al. 2011, Bustnes et al. 2013). Seabirds are known to respond to variations in prey accessibility through their at-sea distribution and foraging behaviour (Hunt et al. 1999). As demonstrated here, oceanographic factors governing food accessibility and industrial fisheries catches may shape the population dynamics of these marine top predators in an upwelling ecosystem. Eastern boundary upwelling ecosystems support very large seabird populations, both resident and non-breeding visitors (Gaston 2004). These ecosystems are characterised by relatively shallow ULOMZs and there is evidence for changes in the depth of the ULOMZ in response to climate change (Diaz and Rosenberg 2008, Stramma et al. 2008), which should also reduce forage fish capacity (Brochier et al. 2013). Therefore, quantifying the effect of prey accessibility and prey removal by fisheries on top predator demography and dynamics should be part of future research in upwelling ecosystems, and more generally in other marine ecosystems.

Acknowledgements - We thank Jean-Michel Gaillard for help at improving an earlier version of the manuscript.

Funding - This work was supported by the cooperative agreement between the Institut de Recherche pour le Développement (IRD), the Peruvian Sea Institute (IMARPE), the Agence Nationale de la Recherche (ANR) project 'Top Predators as Indicators of Exploited Marine Ecosystem dynamics' (TOPINEME), and of the International Joint Laboratory DISCOH.

\section{References}

Aid, C. S. et al. 1985. Range extension of the Peruvian booby to Panama during the 1983 El Nińo. - Colonial Waterbirds 8: 67-68.

Ainley, D. G. et al. 1988. ENSO effects on Pacific Ocean marine bird populations. - In: Ouellet, H. (ed), Proc. XIX Int. Ornithol. Congr. Natl Mus. Nat. Hist., Ottawa, pp. 747-758.

Ashmole, N. P. 1963. The regulation of numbers of tropical oceanic birds. - Ibis 103: 458-473.

Ayón, P. et al. 2011. Long term changes in zooplankton size distribution in the Peruvian Humboldt Current System: conditions favouring sardine or anchovy. - Mar. Ecol. Prog. Ser. 422: 211-222.

Balance, L. T. et al. 2009. An energetic correlate between colony size and foraging effort in seabirds, an example of the Adélie penguin Pygoscelis adeliae. - J. Avian Biol. 40: 279-288.

Barbraud, C. et al. 2012. Effect of climate change and fisheries bycatch on Southern Ocean seabirds: a review. - Mar. Ecol. Prog. Ser. 454: 285-307.

Bertrand, A. et al. 2004. From small-scale habitat loopholes to decadal cycles: a habitat-based hypothesis explaining fluctuation in pelagic fish populations off Peru. - Fish Fish. 5: 296-316.

Bertrand, A. et al. 2008. Schooling behaviour and environmental forcing in relation to anchoveta distribution: an analysis across multiple spatial scales. - Prog. Oceanogr. 79: 264-277.

Bertrand, A. et al. 2010. Acoustic observation of living organisms reveals the upper limit of the oxygen minimum zone. - PloS One 5: e10330. 
Bertrand, A. et al. 2011. Oxygen: a fundamental property regulating pelagic ecosystem structure in the coastal southeastern tropical Pacific. - PLoS One 6: e29558.

Bertrand, A. et al. 2014. Broad impacts of fine-scale dynamics on seascape structure from zooplankton to seabirds. - Nat. Commun. 5: 5239.

Bertrand, S. et al. 2012. Local depletion by a fishery can affect seabird foraging. - J. Appl. Ecol. 49: 1168-1177.

Bost, C. A. et al. 2009. The importance of oceanographic fronts to marine birds and mammals of the southern oceans. - J. Mar. Syst. 78: 363-376.

Brochier, T. et al. 2013. Climate change scenarios experiments predict a future reduction in small pelagic fish recruitment in the Humboldt Current System. - Global Change Biol. 19: 1841-1853.

Bulmer, M. G. 1975. The statistical analysis of density dependence. - Biometrics 31: 901-911.

Bustnes, J. O. et al. 2013. Changes in the Norwegian breeding population of European shag correlated with forage fish and climate. - Mar. Ecol. Prog. Ser. 489: 235-244.

Castillo, S. and Mendo, J. 1987. Estimation of unregistered Peruvian anchoveta (Engraulis ringens) in official catch statistics, 1951-1982. - In: Pauly, D. and Tsukayama, I. (eds), The Peruvian anchoveta and its upwelling ecosystem: three decades of change, no. 15. ICLARM Studies and Reviews, Manila, pp. 109-116.

Charles E. P. 2005. The correction for attenuation due to measurement error: clarifying concepts and creating confidence sets. - Psychol. Meth. 10: 206-226.

Chavez, F. et al. 2008. The Northern Humboldt Current System: brief history, present status and a view towards the future. - Prog. Oceanogr. 79: 95-105.

Crawford, R. J. M., and Jahncke, J. 1999. Comparison of trends in abundance of guano-producing seabirds in Peru and southern Africa. - S. Afr. J. Mar. Sci. 21: 145-156.

Cury, P. M. et al. 2011. Global seabird response to forage fish depletion - one-third for the birds. - Science 334: 1703-1706.

Daunt, F. et al. 2007. From cradle to early grave: juvenile mortality in European shags Phalacrocorax aristotelis results from inadequate development of foraging proficiency. - Biol. Lett. 3: 371-374.

Delean, S. et al. 2013. Ecologically realistic estimates of maximum population growth using informed Bayesian priors. - Meth. Ecol. Evol. 4: 34-44.

Dennis, B. and Taper, M. L. 1994. Density-dependence in time-series observations of natural populations - estimation and testing. - Ecol. Monogr. 64: 205-224.

Dennis, B. and Otten, M. R. M. 2000. Joint effects of density dependence and rainfall on abundance of San Joaquin kit fox. - J. Wildl. Manage. 64: 388-400.

Dennis, B. et al. 2006. Estimating density dependence, process noise and observation error. - Ecol. Monogr. 76: 323-341.

Diaz, R. J. and Rosenberg, R. 2008. Spreading dead zones and consequences for marine ecosystems. - Science 321: 926-929.

Duffy, D. C. 1983. Environmental uncertainty and commercial fishing: effects on Peruvian guano birds. - Biol. Conserv. 26: 227-238.

Duffy, D. C. 1990. Seabirds and the 1982-1984 El Niño-Southern Oscillation. - In: Glynn, P. W. (ed.), Global ecological consequences of the 1982-83 El Nino Southern Oscillation. Elsevier Oceanogr. Ser. 52.
Duffy, D. C. 1994. The guano islands of Peru: the once and future management of a renewable resource. - Birdlife Conserv. Ser. 1: 68-76.

Enstipp, M. R. et al. 2006. The effects of depth, temperature and food ingestion on the foraging energetics of a diving endotherm, the double-crested cormorant (Phalacrocorax auritus). - J. Exp. Biol. 209: 845-859.

Estes, J. A. et al. 2011. Trophic downgrading of planet earth. - Science 333: 301-306.

Frederiksen, M. et al. 2004. The role of industrial fisheries and oceanographic change in the decline of North Sea black-legged kittiwakes. - J. Appl. Ecol. 41: 1129-1139.

Fuenzalida, R. et al. 2009. Vertical and horizontal extension of the oxygen minimum zone in the eastern South Pacific Ocean. - Deep Sea Res. II 56: 992-1003.

Furness, R. W. 2007. Responses of seabirds to depletion of food fish stocks. - J. Ornithol. 148: S247-S252.

Garcia, H. E. et al. 2010. World Ocean Atlas 2009, Vol. 3. Dissolved oxygen, apparent oxygen utilisation and oxygen saturation. - NOAA Atlas NESDIS 70, US Govern. Printing Office, Washington.

Gaston, A. 2004. Seabirds a natural history. - T \& AD Poyser.

Gelman, A. and Rubin, D. B. 1992. Inference from iterative simulation using multiple sequences. - Stat. Sci. 7: 457-511.

Goya, E. 2000. Abundancia de aves guaneras y su relación con la pesquería de anchoveta peruana de 1953 a 1999. - Bol. Inst. Mar. Peru 19: 125-131.

Grados, D. et al. 2012. Multiscale characterization of spaital relationships among oxycline depth, macrozooplankton, and forage fish off Peru using geostatistics, principal coordinates or neighbour matrices (PCNMs) and wavelets. - Can. J. Fish. Aquat. Sci. 69: 740-754.

Guillén, V. C. 1992. Distribución latitudinal de aves guaneras del Perú, durante 1984-1989. - Bol. Lima 81: 77-96.

Gutierrez, M. et al. 2007. Anchovy (Engraulis ringens) and sardine (Sardinops sagax) spatial dynamics and aggregation patterns in the Humboldt Current ecosystem, Peru, from 1983-2003. - Fish. Oceanogr. 16: 155-168.

Hastie, T. 2011. GAM: generalized additive models. - R package ver. $1.04<$ http://cran.r-project.org/web/packages/gam/index. html $>$.

Herdson, D. 1984. Changes in the demersal fish stocks and other marine life in Ecuadorian coastal waters during the 1982-83 El Niño. - Trop. Ocean. Atmos. Newslett. 28: 14.

Hughes, R. A. 1985. Notes on the effects of El Nińo on the seabirds of the Mollendo district, southwest Peru, in 1983. - Ibis 127: 385-388.

Hunt, G. L. and Schneider, D. C. 1987. Scale-dependent process in the physical and biological environment of marine birds. - In: Croxall, J. P. (ed.), Seabirds: feeding ecology and role in marine ecosystems, Cambridge Univ. Press, pp. 7-42.

Hunt, G. L. et al. 1999. Physical processes, prey abundance, and the foraging ecology of seabirds. - In: Adams, N. J. and Slotow, R. H (eds), Proc. 22 Int. Ornithol. Congr., BirdLife South Africa, pp. 2040-2056.

Jahncke, J. 1998. Las poblaciones de aves guaneras y sus relaciones con la abundancia de anchoveta y la ocurrencia de eventos El Niño en el mar Peruano. - Bol. Inst. Mar. Peru 17: $1-14$.

Jahncke, J. et al. 2004. Trends in carbon flux to seabirds in the Peruvian upwelling system: effects of wind and fisheries on population regulation. - Fish. Oceanogr. 13: 208-223. 
Jordán, R. 1963. Resultados de los censos gráficos de las aves guaneras efectuados en noviembre de 1960 y enero de 1962. - Inf. Inst. Invest. Recurs. Mar. 12: 1-20.

Jordán, R. 1967. The predation of guano birds on the Peruvian anchovy (Engraulis ringens JENYNS). - California Cooperative Oceanic Fisheries Investigations Report 11: 105-109.

Knape, J. and de Valpine, P. 2012. Are patterns of density dependence in the Global Population Dynamic Database driven by uncertainty about population abundance? - Ecol. Lett. 15: 17-23.

Lawrence, J. D. et al. 2013. The importance of prior choice in model selection: a density dependent example. - Methods Ecol. Evol. 4: 25-33.

Lebreton, J. D. 2009. Assessing density-dependence: where are we left? - In: Thomson, D. L. et al. (eds), Modeling demographic processes in marked populations, Springer, pp. 19-42.

Lebreton, J. D. and Gimenez, O. 2013. Detecting and estimating density dependence in wildlife populations. - J. Wildl. Manage. 77: 12-23.

Mendo, J. and Wosnitza-Mendo, C. 2014. Reconstruction of total marine fisheries catches for Peru: 1950-2010. - Fisheries Centre Working Paper $<$ www.fisheries.ubc.ca/node/4717 $>$.

Murphy, R. C. 1936. Oceanic birds of South America. - Am. Mus. Nat. Hist.

Nelson, J. B. 2005. Pelicans, cormorants, and their relatives. - Oxford Univ. Press.

Niel, C. and Lebreton, J.-D. 2005. Using demographic invariants to detect overharvested bird populations from incomplete data. - Conserv. Biol. 19: 826-835.

Oliveros-Ramos, R. and Peña, C. 2011. Modeling and analysis of the recruitment of Peruvian anchovy (Engraulis ringens) between 1961 and 2009. - Ciencias Marinas 37: 659-674.

Passuni, G. et al. 2016. Seasonality in marine ecosystems: Peruvian seabirds, anchovy and oceanographic conditions. - Ecology 97: 182-193.

Paulmier, A. and Ruiz-Pino, D. 2009. Oxygen minimum zones (OMZs) in the modern ocean. - Prog. Oceanogr. 80: 113-128.

Plummer, M. 2003. JAGS: a program for analysis of Bayesian graphical models using Gibbs sampling. - Proc. 3rd Int. Workshop on Distributed Statistical Computing, Vienna.

Rykaczewski, R. R and Checkley, D. M. 2008. Influence of ocean winds on the pelagic ecosystem in upwelling regions. - Proc. Natl Acad. Sci. USA 105: 1965-1970.

Schreiber, E. A. 2002. Climate and weather effects on seabird. - In: Schreiber, E. A. and Burger, J. (eds), Biology of marine birds. CRC Press, pp. 179-216.

Schreiber, R. W. and Schreiber, E. A. 1984. Central Pacific seabirds and the El Niño Southern Oscillation: 1982 to 1983 perspectives. - Science 225: 713-716.

Supplementary material (Appendix ecog-02485 at $<$ www. ecography.org/appendix/ecog-02485>). Appendix 1-9.
Shealer, D. A. 2002. Foraging behaviour and food of seabirds. - In: Schreiber, E. A. and Burger, J. (eds), Biology of marine birds. CRC Press, pp. 137-177.

Slade, N. A. 1977. Statistical detection of density dependence from a series of sequential censuses. - Ecology 58: 1094-1102.

Spearman, C. 1904. The proof and measurement of association between two things. - Am. J. Psychol. 15: 72-101.

Spiegelhalter, D. J. et al. 2002. Bayesian measure of model complexity and fit. - J. R. Stat. Soc. B 64: 583-639.

Stenseth, N. C. et al. 2002. Ecological effects of climate fluctuations. - Science 297: 1292-1296.

Stramma, L. et al. 2008. Expanding oxygen-minimum zones in the tropical oceans. - Science 320: 655-658.

Swartzman, G. et al. 2008. The relationship of anchovy and sardine to water masses in the Peruvian Humboldt Current System from 1983 to 2005. - Prog. Oceanogr. 79: 228-237.

Sydeman, W. J. et al. 2012. Seabirds and climate change: roadmap for the future. - Mar. Ecol. Prog. Ser. 454: 107-117.

Tew Kai, E. et al. 2009. Top marine predators track Lagrangian coherent structures. - Proc. Natl Acad. Sci. USA 106: 8245-8250.

Thompson, P. M. and Ollason, J. C. 2001. Lagged effects of ocean climate change on fulmar population dynamics. - Nature 413: 417-420.

Tovar, H. and Cabrera, D. 1985. Las aves guaneras y el fenómeno "El Niño". - Bol. Inst. Mar. Peru vol. Extraordinario: 181-186.

Tovar, H. et al. 1987. Monthly population size of three guano bird species off Peru, 1953 to 1982. - In: Pauly, D. and Tsukayama, I. (eds), The Peruvian anchoveta and its upwelling ecosystem: three decades of change, ICLARM Stud. Rev. 15, pp. 208-218.

Turchin, P. 1999. Population regulation: a synthetic view. - Oikos 84: 153-159.

Weimerskirch, H. et al. 2012. Foraging in Guanay cormorant and Peruvian booby, the major guano-producing seabirds in the Humboldt Current System. - Mar. Ecol. Prog. Ser. 458: 231-245.

Wunderle, J. M. 1991. Age-specific foraging proficiency in birds. - In: Power, D. M. (ed), Current ornithology, Plenum Press, pp. 273-284.

Zavalaga, C. B. and Paredes, R. 1999. Foraging behaviour and diet of Guanay cormorants. - S. Afr. J. Mar. Sci. 21: 251-258.

Zavalaga, C. B. et al. 2010. At-sea movement patterns and diving behavior of Peruvian boobies Sula variegata in northern Peru. - Mar. Ecol. Prog. Ser. 404: 259-274.

Zavalaga, C. B. et al. 2011. Patterns of GPS tracks suggest nocturnal foraging by incubating Peruvian pelicans (Pelecanus thagus). - PLoS One 6: e19966.

Zuur, A. F. et al. 2009. Mixed effects models and extensions in ecology with R. - Springer. 